OBITUARY

\title{
Professor Indira Nath: An unforgettable person
}

\author{
Vishwa Mohan Katoch ${ }^{\mathrm{a}}$ \\ ${ }^{a}$ Rajasthan University of Health Sciences, NASI-ICMR Chair on Public \\ Health, Rajasthan, India \\ e-mail: vishwamohankatoch18@gmail.com
}

Submitted and accepted 17 November 2021

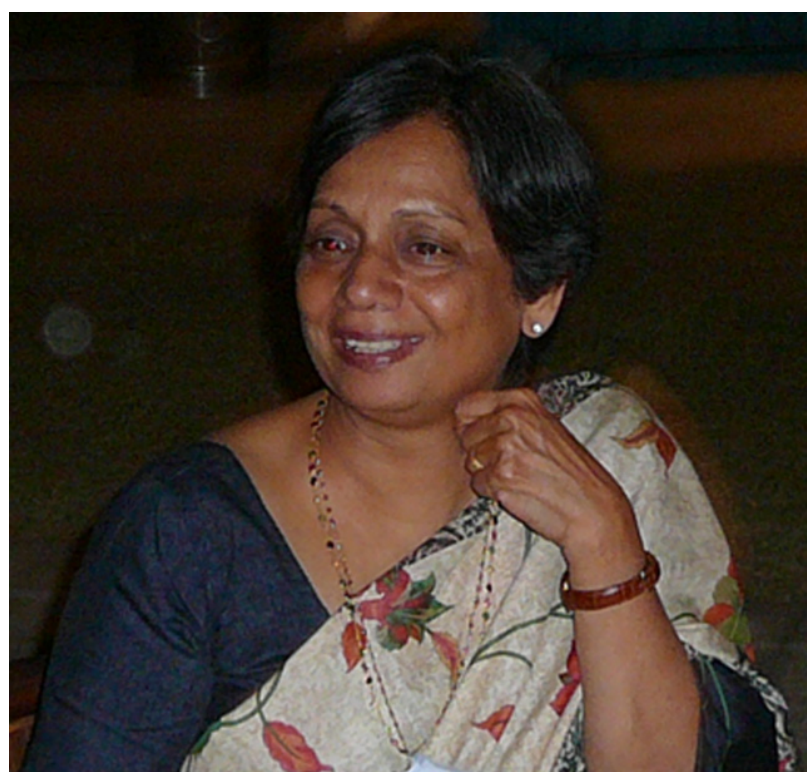

The news of the death of Professor Indira Nath on 24th October, 2021 came as a shock to all those who knew her directly or indirectly. She was 83 years old and had lymphoma for around 8 years. She had responded very well to therapy but relapsed later. Despite these factors all of us wanted her to be on this earth as long as possible and her departure left a vacuum in different spheres - as a person, as an immunologist, as a leprologist, as a mentor, as an advisor, as a policy maker and many other roles in which she continued to contribute till her end. The Organizing Committee for next International Leprosy Congress was looking forward to her advice to plan the agenda and activities. A few days before her death she had given a lot of suggestions to Professor Narasimha Rao, President of the Indian Association of Leprologists 
and Organizing Secretary of the next ILC. As news of her death spread, reactions and tributes poured in through social media. Everybody felt shocked and no one wanted to reconcile to her death!

Having known her perhaps since 1978 onwards, I have many memories of frequently interacting with her and watching her growth, knowing her contributions and lasting impact on science and science management, especially in India. As an immunologist and leprologist she was a global personality in her outlook and actions. She had a huge number of admirers across many countries. She was a collaborator for furthering science within India and also with colleagues outside India. In my opinion what endeared her to scientists and administrators alike was her quest for excellence, brilliance, warmth and then her trait of contributing to the interest of others. Her friends, admirers and collaborators saw in her a genuine and trustworthy person, who will support his/her interests and who will not snatch the genuine credit of others. She was always available to guide and nurture the younger generation.

Right from the late 1970s onwards, we all saw her as a scientist who was in pursuit of originality and impact-making science. Her entire work on the immunology of leprosy and viability of the leprosy bacillus is a testimony to her original contributions to science. Along with her work as a medical teacher and scientist, she was growing as an administrator and science manager. Establishing a department of biotechnology in the best medical institutionAIIMS - was a landmark. This department has made significant contributions in basic and translational aspects of several diseases including tuberculosis, malaria and leprosy.

As her reputation grew, her influence in decision making also increased. She has been member and/or chairperson of a large number of committees in different science agencies: namely, the Indian Council of Medical Research, Department of Science \& Technology, Department of Biotechnology for more than three decades. She chaired the Scientific Advisory Committees of important institutions like ICMR - National Institute of Immunology. Her innings as Director of BPHRC and as a Dean of Medicine in Malaysia are some other examples. As a member of the Editorial Board of the Indian Journal of Leprosy she contributed immensely. She contributed to both government and non-governmental organizations, as well as different professional bodies/associations. She made a great difference in every role she played, received many coveted awards/honours and her impact is everlasting.

Her confidence and commitment even in adverse circumstances was inspiring. When she was battling lymphoma, I had an unforgettable experience about seven years ago. She was scheduled to deliver an oration at my old institution-JALMA Agra, that was committed long back and her chemotherapy had become due exactly on same day. I called her to explore whether we could reschedule the oration. She was clear-no change, she will reschedule the chemotherapy. We both drove to Agra as if her health problem did not exist! When years later it relapsed, again the same confidence and business as usual! Many like me and my wife saw her in many roles-Professor Indira Nath was a family person, wonderful colleague, thought leader with a broad vision of people and science. In her entire life, she remained a symbol of excellence, commitment, fairness, frankness and courage. We will miss her advice, her affection but her life will continue to inspire the present and future generations of leprologists, immunologists/biomedical scientists, especially socially conscious individuals with the goal of making a difference! 